\title{
Biliary Manometric Perfusion Test in Evaluating the Efficacy of Balloon Cholangioplasty for Non-Anastomotic Biliary Strictures after Orthotopic Liver Transplantation
}

DOI: $10.17691 / \mathrm{stm} 2017.9 .4 .07$

Received August 24, 2017

A.A. Polikarpov, MD, DSC, Department of Angiography and Interventional Radiology;

P.G. Tarazov, MD, DSe, Professor, Head of the Department of Angiography and Interventional Radiology;

A.S. Polekhin, MD, Department of Angiography and Interventional Radiology;

A.Y. Moiseenko, MD, Department of Angiography and Interventional Radiology;

K.I. Karakhanov, MD, Department of Anesthesiology and Intensive Care;

V.V. Borovik, MD, PhD, Department of Surgery and Interventional Radiology;

D.A. Granov, MD, DSc, Professor, Corresponding Member of the Russian Academy of Sciences, Deputy Director for Surgery and Interventional Radiology

Russian Research Center for Radiology and Surgical Technologies named after Academician A.M. Granov, 70 Leningradskaya St., Pesochniy pos., Saint Petersburg, 197758, Russian Federation

The aim of the study was to determine the role of biliary manometric perfusion test in evaluating the efficacy of percutaneous balloon cholangioplasty (balloon dilation) for biliary strictures in patients after orthotopic liver transplantation (OLT).

Materials and Methods. During the period of 1998-2016, 168 patients underwent 179 OLTs in the Russian Research Center for Radiology and Surgical Technologies named after Academician A.M. Granov (Saint Petersburg). Non-anastomotic biliary strictures requiring interventional radiological procedures occurred in 15 patients ( $8.4 \%$ of the total number of OLTs) within 3 to 62 months after surgery.

The study involved 6 patients who underwent 43 stricture dilations ( 3 to 14) with balloon catheters of 4 to 8 mm diameter after percutaneous transhepatic cholangiodrainage. External-internal cholangiodrainage of $8 \mathrm{~F}$ diameter was left in place after bilioplasty. Treatment procedures were repeated under intravenous anesthesia once in 2-3 months.

Biliary manometric perfusion test was performed after positive X-ray control of biliary patency within 6 to 17 months from the beginning of bilioplasty. The drains were removed from the guidewire, introducers of 9-10 F diameter were placed in the bile duct above the stricture. $30 \%$ solution of Ultravist- 350 was infused into the ducts in the following modes: $4 \mathrm{ml} / \mathrm{min}$ during $5 \mathrm{~min} ; 8 \mathrm{ml} / \mathrm{min}-5 \mathrm{~min}$; $15 \mathrm{ml} / \mathrm{min}-3 \mathrm{~min} ; 20 \mathrm{ml} / \mathrm{min}-2 \mathrm{~min}$. Fluid pressure was measured within the ducts before and after the infusion. The result of balloon dilation was considered successful if the pressure before and after the infusion did not exceed $200 \mathrm{~mm}$ WG. In these cases, externalinternal drain was removed.

Results. Based on the manometry data, 9 drains were successfully removed in all 6 patients during the period of 8 to 22 months from the time of cholangiodrainage. The patients were followed up for 4 to 40 months without radiographic and biochemical signs of biliary hypertension and cholestasis.

Conclusion. Biliary manometric perfusion test may serve as an effective minimally invasive method to control the efficacy of balloon cholangioplasty for biliary strictures in patients after orthotopic liver transplantation. ducts.

Key words: biliary manometric perfusion test; biliary strictures; orthotopic liver transplantation; balloon cholangioplasty of the bile

Bile duct stricture (biliary stricture) occur after orthotopic liver transplantation (OLT) in 10-25\% of cases [1, 2]. With the development of anastomotic stricture between donor and recipient bile duct parts, the method of choice for its correction is endoscopic balloon cholangioplasty with subsequent placement of a temporary stent. Technical success of the procedure reaches $90-100 \%$, with bile duct patency maintained for 3 years in $70 \%$ of patients [3, 4$]$.

High non-anastomotic strictures usually develop in the long term after OLT and are associated with ischemia of the bile ducts [5-7]. Traditional methods of surgical, endoscopic, or percutaneous stricture dilation lead to recurrence of jaundice within 6 to 8 months after drain removal in $20-60 \%$ of patients [8, 9]. Thus, the optimal timing of drainage removal is vitally important, which determines the significance of evaluating balloon dilation for strictures after OLT qualitatively.

The aim of the study was to determine the role of biliary manometric perfusion test in evaluating the

For contacts: Alexey A. Polikarpov, e-mail: pol1110@mail.ru 
efficacy of percutaneous balloon cholangioplasty for biliary strictures in patients after orthotopic liver transplantation.

Materials and Methods. During the period of 1998-2016, 168 patients underwent 179 OLTs in the Russian Research Center for Radiology and Surgical Technologies named after Academician A.M. Granov (Saint Petersburg). Non-anastomotic biliary strictures requiring endoscopic/percutaneous drainage occurred in 15 patients $(8.4 \%$ of the total number of OLTs) within 3 to 62 months after surgery.

The following interventions were used to treat the strictures: endoscopic retrograde stenting of bile ducts 5; percutaneous transhepatic stenting - 4; bilateral percutaneous transhepatic cholangiodrainage -3 ; right cholangiodrainage -3 .

The study involved 6 out of 15 patients who underwent percutaneous transhepatic cholangiodrainage. On day 5-14 after jaundice and cholangitis were relieved,
43 stricture dilations (3 to 14) with balloon catheters (Mustang; Boston Scientific, Ireland; Powerflex; Cordis, USA) of 4 to $8 \mathrm{~mm}$ in diameter were performed under intravenous anesthesia to full deployment with fixation for 2-3 min. External-internal cholangiodrainage of $8 \mathrm{~F}$ diameter (Cook, USA) was left in place after cholangioplasty. The procedures were repeated once in 2-3 months (Figure 1).

The study complies with the Declaration of Helsinki (the Declaration was passed in Helsinki, Finland, June 1964 and revised in Edinburgh, Scotland, October 2000) and was performed following approval by the Ethics Committee of the Russian Research Center for Radiology and Surgical Technologies named after Academician A.M. Granov. Written informed consent was obtained from every patient.

Biliary manometric perfusion test (BMPT) [10] was performed after positive X-ray control of biliary patency 6 to 17 months after the first bilioplasty. The
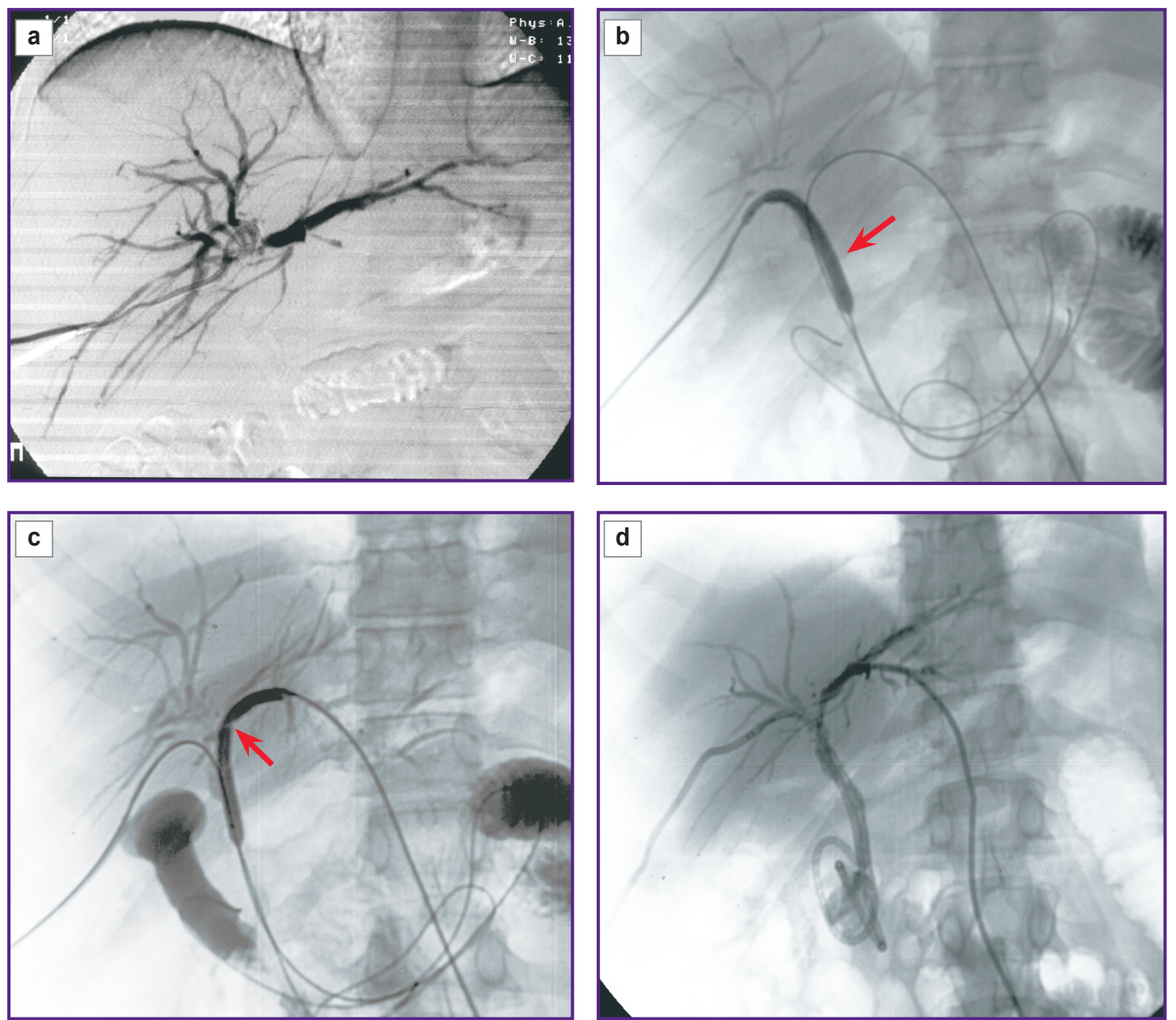

Figure 1. Radiographs of patient B., 37 years of age; 42 months after orthotopic liver transplantation:

(a) cholangiogram after percutaneous drainage: complete blockage at the level of bifurcation of the lobar bile ducts; (b) right lobar duct dilation; balloon catheter fully deployed to $6 \mathrm{~mm}$ (arrow); (c) during left lobar duct dilation, "waist" is visualized on the balloon catheter at the stricture site (arrow); (d) control cholangiogram after balloon dilation: bilateral drains are placed through the lobar ducts and the choledoch duct in the duodenum; the bile ducts are collapsed, the contrast flows freely into the duodenum 


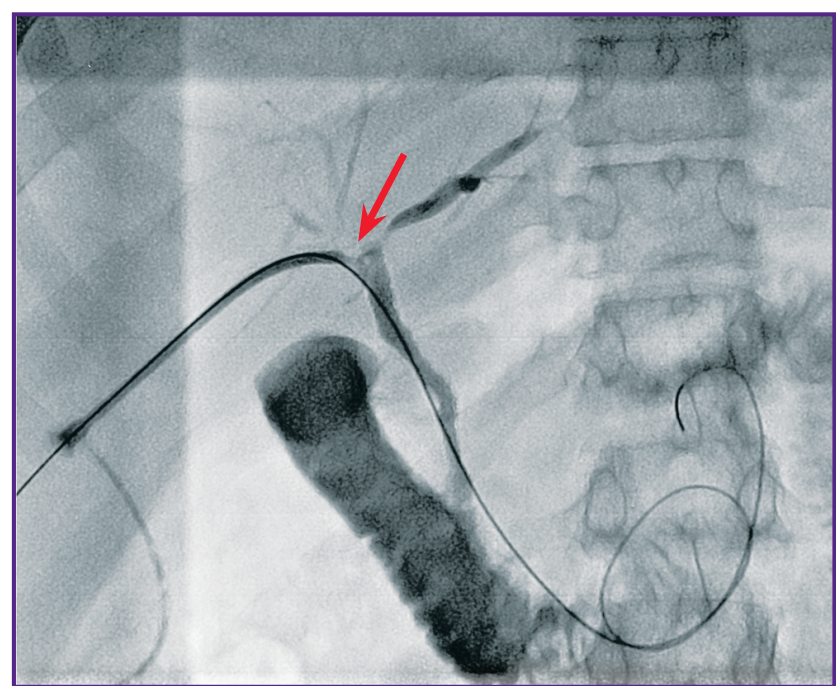

Figure 2. Cholangiography during biliary manometric perfusion test:

The introducer is placed in the entrance of the right lobar duct above the stricture (arrow); the guidewire is in the duodenum; $30 \%$ solution of Ultravist-350 is infused through the introducer

drains were removed from the guidewire, introducers (Cordis, USA; Terumo, Japan) of 9-10 F diameter (1 or $2 \mathrm{~F}$ more than the previously placed drain) were inserted in the lobar bile duct above the stricture. Thus, a leak-free system was created to measure the pressure inside the ducts and perform infusion. The guidewire was replaced with another one of 0.18 with hydrophilic coating. Cholangiography with $30 \%$ solution of Ultravist-350 (Bayer, Germany) was carried out. Once good evacuation of the contrast solution in the duodenum, the absence of "leaks" and endoleaks were proved, the pressure inside the ducts was measured via a three-way tap using Infiniti HemoMed apparatus (Dräger, Germany) for monitoring invasive pressure. Initial pressure of less than $200 \mathrm{~mm}$ WG within the bile ducts was considered to be an indication for BMPT [11]. On switching the three-way tap, $30 \%$ solution of Ultravist-350 was infused into the ducts using Infusomat Space (B. Braun, Germany) in the following modes: $4 \mathrm{ml} / \mathrm{min}$ during $5 \mathrm{~min} ; 8 \mathrm{ml} / \mathrm{min}-5 \mathrm{~min} ; 15 \mathrm{ml} / \mathrm{min}-$ $3 \mathrm{~min} ; 20 \mathrm{ml} / \mathrm{min}-2 \mathrm{~min}$ (Figure 2).

In case of bursting pain in the epigastrium, nausea, vomiting, chills, the test was considered negative and the procedure was stopped. In the absence of clinical complaints before and after each infusion, fluid pressure inside the ducts was measured by switching the threeway tap without separating the leak-free system. The result of balloon dilation was considered successful if pressure gradient before and after the infusion did not exceed $150 \mathrm{~mm}$ WG. In these cases, external-internal drain was finally removed. In three cases of bilateral drainage, BMPT was performed alternately in one procedure.
Results. Based on positive manometry data, 6 drainages were successfully removed in 4 patients within 8 to 22 months (median, 15) after the first BMPT.

Despite the excellent results in the control cholangiography within 6 and 16 months, the pressure in the ducts of two patients after repeated balloon dilation measured more than $200 \mathrm{~mm}$ WG when $30 \%$ solution of Ultravist-350 was infused into the ducts at 8 $\mathrm{ml} / \mathrm{min}$ speed for $5 \mathrm{~min}$. In this connection, BMPT result was found negative. Repeated balloon dilation was performed, the drains in place. Repeated cholangioplasty and BMPT were carried out with a positive results after 2 and 3 months, the drains being removed.

So far, all 6 patients have been followed up for 4 to 40 months since the drains were removed without clinical, radiographic and biochemical signs of biliary hypertension and cholestasis (Figure 3).

Discussion. Today, percutaneous balloon dilation with subsequent drainage plays the leading role in management of high non-anastomotic benign biliary strictures after OLT [5, 8]. Despite the advances in methods of radiation imaging (multi-slice spiral CT, MRI with cholangiopancreatography, endoscopic ultrasound), it seems impossible to clearly determine the timescales of scar tissue formation and reliably confirm functional patency of the bile ducts [3, 12]. In recent years, the drains have been removed after 24 months in case of a good X-ray picture of contrast material evacuation and/ or after positive biochemical test (no increase in blood alkaline phosphatase and bilirubin within 3,5 , and 7 days when drains migrate above the stricture). Both methods have certain drawbacks: the first method requires regular changing the drains during 24 months, the second suggests the risk of control drainage migrating from the liver parenchyma. Notably, the frequency of

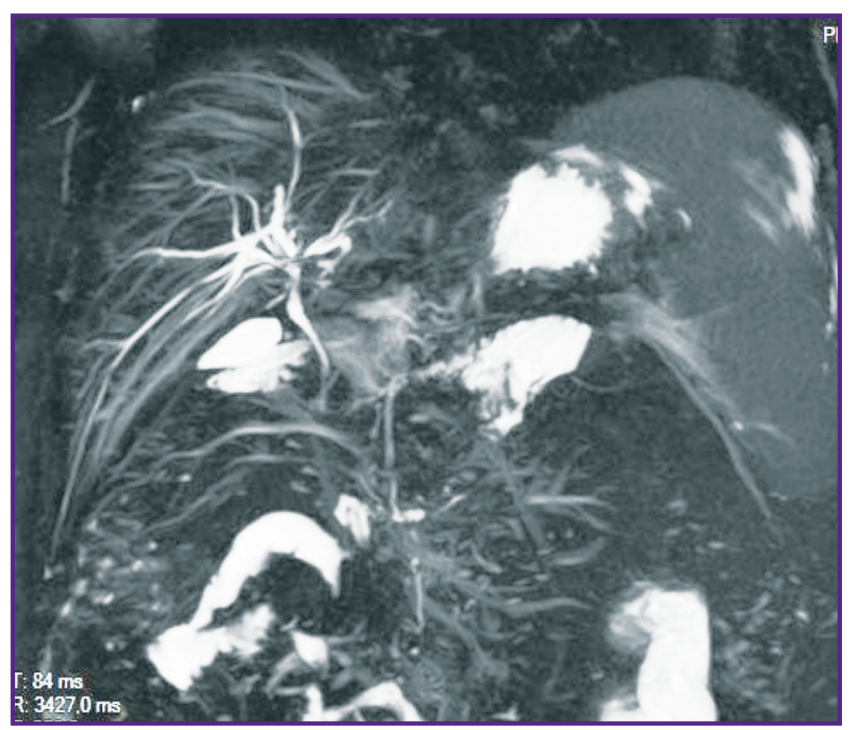

Figure 3. Magnetic resonance cholangiography 18 months after drain removal; no signs of biliary hypertension 
stricture recurrence after drain removal ranges from 9 to $33 \%$ in the first five years, according to biochemical test results [10].

In 1998, Savader et al. [10] proposed to use BMPT for assessment of bile duct patency after surgical/ percutaneous biliary drain placement. The test was considered successful if the pressure inside the bile ducts before and after perfusion of $50 \%$ contrast agent did not exceed $200 \mathrm{~mm}$ WG. The authors made Kaplan-Meier curves to predict bile duct patency in two randomized groups of patients: after BMPT and biochemical test. The final positive outcome of repeated treatment procedures (balloon dilation) during 4 years was observed in 80 and $88 \%$ of patients in groups after BMPT and biochemical test, respectively $(p>0.05)$. The authors believe that using BMPT may reveal bile outflow abnormalities in the early stages of treatment which makes it a promising method to estimate long-term bile duct patency $[9,10]$.

We have performed percutaneous balloon dilations of benign bile duct strictures in patients without OLT since 1996. As a rule, the drains were removed 24 months after positive biochemical test. Recurrence of biliary hypertension was acceptable (11\%), but required reintervention. However, in patients after liver transplantation, this approach is inappropriate: longterm percutaneous drainage can lead to life-threatening infectious complications and graft dysfunction [1, 3]. Therefore, we decided to use BMPT in this category of patients as early as possible: immediately after obtaining a good X-ray picture of contrast agent evacuation. Based on Galperin's early studies on manometric and flow measurement evaluations of bile ducts [11], we have found that BMPT should be carried out only if the initial pressure inside the bile ducts does not exceed $200 \mathrm{~mm}$ WG. In the process of $50 \%$ contrast agent infusion, there were no clinical complaints from our patients. However, when the outflow was increased in two patients, the pressure in the bile ducts exceeded $200 \mathrm{~mm}$ WG, which was the reason to continue balloon dilation procedures. In control examination, BMPT was considered to be a success and the drains were removed. Today, all the patients have been followed up, there are no indications for reintervention.

Conclusion. Biliary manometric perfusion test is considered to be an effective minimally invasive method to control the efficacy of balloon cholangioplasty for biliary strictures in patients after orthotopic liver transplantation.

Study Funding and Conflict of Interests. This study was not supported by any financial sources and the authors have no conflict of interests to disclose.

\section{References}

1. Gautier S.V., Moysyuk Y.G., Poptsov V.N., Kornilov M.N., Tsirulnikova O.M., Yaroshenko E.B., Miloserdov I.A., Pogrebnichenko I.V., Belskikh L.V. One hundred deceased donor liver transplantations at a single center. Russian Journal of Transplantology and Artificial Organs 2012; 14(1): 6-14.

2. Wang S.F., Huang Z.Y., Chen X.P. Biliary complications after living donor liver transplantation. Liver Transpl 2011; 17(10): 1127-1136, https://doi.org/10.1002/lt.22381.

3. Gwon D.I., Sung K.-B., Ko G.-Y., Yoon H.-K., Lee S.-G. Dual catheter placement technique for treatment of biliary anastomotic strictures after liver transplantation. Liver Transpl 2011; 17(2): 159-166, https://doi.org/10.1002/lt.22206.

4. Kulaksiz H., Weiss K.H., Gotthardt D., Adler G., Stremmel W., Schaible A., Dogan A., Stiehl A., Sauer P. Is stenting necessary after balloon dilation of post-transplantation biliary strictures? Results of a prospective comparative study. Endoscopy 2008; 40(9): 746-751, https://doi. org/10.1055/s-2008-1077489.

5. Shin M., Joh J.-W. Advances in endoscopic management of biliary complications after living donor liver transplantation: comprehensive review of the literature. World J Gastroenterol 2016; 22(27): 6173, https://doi.org/10.3748/ wjg.v22.i27.6173.

6. Axelrod D.A., Dzebisashvili N., Lentine K.L., Xiao H., Schnitzler M., Tuttle-Newhall J.E., Segev D.L. Variation in biliary complication rates following liver transplantation: implications for cost and outcome. Am J Transplant 2014; 15(1): 170-179, https://doi.org/10.1111/ajt.12970.

7. Moreira A.M., Carnevale F.C., Tannuri U., Suzuki L., Gibelli N., Maksoud J.G., Cerri G.G. Long-term results of percutaneous bilioenteric anastomotic stricture treatment in liver-transplanted children. Cardiovasc Intervent Radiol 2009; 33(1): 90-96, https://doi.org/10.1007/s00270-009-9619-2.

8. Lee D.W., Jo H.H., Abdullah J., Kahaleh M. Endoscopic management of anastomotic strictures after liver transplantation. Clin Endosc 2016; 49(5): 457-661, https://doi. org/10.5946/ce.2016.130.

9. Thomas R.P., Köcher M. Percutaneous treatment of benign biliary strictures and biliary manometric perfusion test. Biomed Pap Med Fac Univ Palacky Olomouc Czech Repub 2007; 151(1): 85-90, https://doi.org/10.5507/ bp.2007.015.

10. Savader S.J., Cameron J.L., Lillemoe K.D., Lund G.B., Mitchell S.E., Venbrux A.C. The biliary manometric perfusion test and clinical trial - long-term predictive value of success after treatment of bile duct strictures: ten-year experience. J Vasc Interv Radiol 1998; 9(6): 976-985, https:Ildoi. org/10.1016/s1051-0443(98)70436-1.

11. Galperin E.I., Kunichan M.D. Manometric and flow measurement study of bile ducts. Khirurgiya 1969; 8, 74-78.

12. Mikushkin O.N., Maslorskiy L.V. The diagnosis and treatment of functional disorders of the biliary tract. Gastroenterologiya Sankt-Peterburga 2010, 2-3: 27-32. 